\title{
Evaluation of effect of coconut milk on anxiety
}

\begin{abstract}
Anxiety is a feeling of uneasiness, nervousness and fear, which can lead to a serious mental illness. Currently the trend of population suffering from anxiety is increasing. The study has been designed to evaluate the anxiolytic potential of coconut milk. The study was carried out on albino mice weighing $18-25 \mathrm{gm}$ either male or female. Mice were divided into 3 groups. Group I was taken as Control and given distilled water $0.4 \mathrm{ml}$. Group II was taken as treated and given coconut milk $0.4 \mathrm{ml}$ and Group III was given $0.6 \mathrm{ml}$ of coconut milk. Head dip, light and dark model, cage crossing, open field and elevated plus maze were used to evaluate coconut milks effect on anxiety. Our study exposed significant effects of anxiolytic activity of coconut milk in mice. Head dip activity and open field activity show highly significant result. We conclude that administration of coconut milk gives anxiolytic effects because it possesses anti-oxidant components as multi vitamins and minerals. It has less adverse effect as compared to allopathic drugs, we can use coconut milk in our daily diet.
\end{abstract}

Keywords: anxiolytic, coconut milk, memory boosting

\author{
Volume 6 Issue 4 - 2017
}

\author{
Sidra Zubair,' Sana Sarfaraz,' Safila Naveed, ${ }^{2}$ \\ Ghulam Sarwar ${ }^{3}$ \\ 'Department of Pharmacology, Jinnah University for Women, \\ Pakistan \\ ${ }^{2}$ Department of Pharmaceutical Chemistry, Jinnah University for \\ Women, Pakistan \\ ${ }^{3}$ Department of Pharmacognosy, Jinnah University for Women, \\ Pakistan
}
Correspondence: Sana Sarfaraz, Assistant Professor at Department of Pharmacology, Faculty of Pharmacy, Jinnah University for women, 5c Nazimabad Karachi-74600, Pakistan, Emailsana.sarfraz@live.com

Received: October 15, 2017 | Published: November 21, 2017
Abbreviations: ANOVA, analysis of variance; CBT, cognitive behavior therapy; GABA, gamma amino butyric acid; GAD, generalized anxiety disorder; OCD, obsessive compulsive disorder; SAD, social anxiety disorder; PTSD, post-traumatic stress disorder; SNRI, serotonin norepinephrine reuptake inhibitors; SPSS, statistical package for social sciences; SSRI, selective serotonin reuptake inhibitors; TCAs, tricyclic antidepressants

\section{Introduction}

Anxiety is an emotion or it is a feeling of discomfort, nervousness, apprehension, fear or worry. If it occurs for a short period, it is a normal reaction but if prolonged at a regular basis, it can be a serious mental illness. ${ }^{1}$ It disturbs the normal routine life of a person. It is accompanied by fatigue and restlessness. It creates difficulty in focusing. Anxiety may be due to stress, alcohol intake, ${ }^{2}$ caffeine or due to some drug withdrawal. It might occur with other mental disorders ${ }^{3}$ like major depressive disorder or bipolar disorder etc. Another cause is reduced level of inhibitory neurotransmitter like GABA (gamma amino butyric acid). ${ }^{4}$

There are major six types of anxiety disorders. Generalized anxiety disorder (GAD), a chronic disorder ${ }^{5}$ in which a person has a persistent feeling that something bad or wrong might occur. GAD patients feel nervousness all the time without any reason. It keeps them from concentrating. In Panic disorder, person gets a short lived and sudden attack of anxiety, in which discomfort arises less than 10minutes and lasts to several hours, this attack can be triggered due to some stress or fear. Obsessive-compulsive disorder (OCD) is a persistent and uncontrollable feeling and behavior ${ }^{6}$ in which people feel the need to check things repeatedly. Phobic disorder is the largest category of anxiety that includes all type of fear or phobia from specific object or situation. Social anxiety disorder (SAD), includes intense fear of social interaction and public embarrassment. It is also known as social phobia. ${ }^{7}$ Performance anxiety is the most common type of SAD. Posttraumatic stress disorder (PTS) results from any extreme trauma, natural disaster or life-threatening event. ${ }^{8}$

General symptoms of all anxiety disorders includes Palpitation, dry mouth, muscular tension, trembling, nausea, feeling uneasiness, insomnia, difficulty in focus, restlessness and irritability. Anxiety can be due to genetics but external stimuli can also trigger its onset or any underlying disease such as sleep apnea, chronic obstructive pulmonary disease, Parkinson's disease, ${ }^{9}$ rheumatoid arthritis, ${ }^{10}$ cancer or diabetes, history of trauma, ${ }^{11}$ parenting factors, ${ }^{12}$ cultural factors etc.

Treatment can be variable according to the intensity of anxiety. Normally anxiety is treated by changes in dietary intake and life style modification. Psychotherapy is also used to treat anxiety. ${ }^{13}$ Cognitive behavior therapy (CBT) is a psychological treatment that can also be done to treat anxiety. ${ }^{14}$

Medications are used when there is insufficient response from psychotherapy or they may be used as initial treatment of an anxiety disorder. A combination of medication and psychotherapy can be more effective. ${ }^{15}$ Antidepressants are used as a first line treatment for anxiety. Selective Serotonin Reuptake Inhibitors (SSRIs) are suggested as first line agent. ${ }^{16}$ Serotonin norepinephrine reuptake inhibitors (SNRIs) and Tricyclic antidepressants (TCAs) are effective treatment. The most commonly used anxiolytics also include Benzodiazepine. Benzodiazepines are also often used as second line treatment because it disturbs sleep pattern. It is only recommended for those patients who fail to respond to safer and effective medication i.e. SSRIs. Dietary and lifestyle changes like Regular exercise and reduce caffeine consumption also reduces anxiety. Especially aerobic exercise has a calming effect. ${ }^{17}$ Due to the adverse effect of these drugs, we have moved to natural therapy.

Coconut milk is nutritious; it is rich in fiber, vitamins (Vit $\mathrm{C}, \mathrm{E}$. B1, B3, B5\& B6) and minerals. It is lactose free so lactose intolerance patient can use this milk. A $100 \mathrm{ml}$ serving of canned coconut milk contains 154 calories, $1.4 \mathrm{~g}$ protein, $15 \mathrm{~g}$ fats and $3.4 \mathrm{~g}$ carbohydrates. ${ }^{18}$ It contains vitamin-C $6.7 \mathrm{mg}$, vitamin-E $0.4 \mathrm{mg}$, vitamin-K $0.2 \mathrm{mcg}$, niacin $1.8 \mathrm{mg}$, folate $38.4 \mathrm{mcg}$, vitamin-B6 $0.1 \mathrm{mg}$, thiamine $0.1 \mathrm{mg}$, calcium $3.4 \mathrm{mg}$, iron $3 \mathrm{mg}$, magnesium $8.8 \mathrm{mg}$, potassium $631 \mathrm{mg}$, phosphorus $240 \mathrm{mg}$, zinc $1.6 \mathrm{mg}$, manganese $2.2 \mathrm{mg}$, copper $0.6 \mathrm{mg}$ and selenium $14.9 \mathrm{mcg}$.

New research shows that coconut oil is effective in preventing and treating neurodegenerative disease states with a very fresh supply of energy to the brain that prevents unnecessary short-term symptoms. ${ }^{19}$ It contains high level of saturated fats, which gives instant energy to 
the body ${ }^{20}$ several antioxidant compounds, which provide protection from free radicals and lauric acid, ${ }^{21}$ which is converted in the body to monolaurin, which has antiviral and antibacterial property and also promotes brain and bone development. It relieves from stomach \& mouth ulcer and acid reflux disease, improves the digestive system, treats anemia, control the blood sugar level and lower blood pressure, relaxes the nerve and muscles and reduces joint inflammation. It is an excellent source of vitamin E, which is good for skin and hair. It has cooling property. Consuming excessive amounts of coconut meat, oil or milk gives side effect of weight gain due to high calories. The present study has been designed to evaluate the anxiolytic potential of Coconut milk at different doses.

\section{Materials and methods}

\section{Experimental animals}

This study was carried out on albino mice either male or female having weight between 18-25 gm. They were bred and kept in animal house of Jinnah University for women. The animals were given food and water ad libitum, and were kept under constant environmental conditions of $23 \pm 2^{\circ} \mathrm{C}$.

\section{Dosing regime}

The mice were equally divided into 3 groups each group containing 8 mice. Group I was taken as Control and given distilled water $0.4 \mathrm{ml}$. Group II was taken as treated and given coconut milk $0.4 \mathrm{ml}$ and Group III was given $0.6 \mathrm{ml}$ of coconut milk. All groups were given dose orally once daily. The study was carried out for 15 days.

\section{Coconut milk}

Coconut milk was purchased from local market and verified by Department of Pharmacognosy, Faculty of Pharmacy Jinnah University for Women.

Following CNS parameters were conducted on albino mice.

\section{Head dip test}

The apparatus of this test consists of a hole board which is an enclosed wooden rectangular box having an area of $35 \mathrm{~cm} \times 45 \mathrm{~cm} \times$ $45 \mathrm{~cm}$. This box contains holes of $2.5 \mathrm{~cm}$ in diameter. Three holes are found in all four walls. ${ }^{22}$ Mice were familiarized with environment before starting the test. Mice were individually placed in the centre of the hole board and allowed to move freely in the box for 5 minutes. The number of holes explored by mice is the measure of the head dips test. ${ }^{22,23}$ After each reading apparatus was cleared with $70 \%$ alcohol. ${ }^{24}$

\section{Cage crossing activity}

This activity was performed in the transparent, Plexiglas cage $(26 \times 26 \times 26 \mathrm{~cm})$ apparatus. The mouse was placed in the centre of the Plexiglas cage gently by its tail. The mouse was allowed to move for 5 minutes and the number of times mouse crosses the cage was observed. After performing test, apparatus was cleaned with $70 \%$ alcohol.

\section{Open field test}

Open field test was used to determine general locomotory activity and exploratory activity of mice. Assessment took place in a white Plexiglas box with walls $42 \mathrm{~cm}$ high, its floor is marked into 25 squares with a diameter of $15 \mathrm{~cm}$ each. In the middle arena of this apparatus, a $15 \times 15 \mathrm{~cm}$ central square is present.

The albino mouse was placed in the center of arena gently by the tail. The animal was allowed to move freely for 5 minutes. The numbers of times the mouse moved in peripheral and central squares were recorded. After performing experiment, the apparatus was cleaned with $70 \%$ alcohol.

\section{Light and dark test}

This test was designed by Crawley and Goodwin (1980). Rodents generally favor dark areas. The apparatus of this test consists of two compartments, one is small dark compartment, painted black, it is covered by black lid, other compartment has transparent sides, it is covered by transparent lid, and this compartment is illuminated with lamp. This test may be useful to predict anxiolytic or anxiogenic activity of mice.

Mice were familiarized with the surrounding where the apparatus was placed. The mice were transferred individually in the center of the brightly illuminated compartment. Mice were free to move in light and dark compartments for 5 minutes. The time spent in each compartment by mice was observed..$^{25}$

\section{Elevated plus maze test}

This test may be used to check the anxiolytic or anxiogenic activity of mice. In this test, we used plus shaped apparatus, in which two arms are enclosed with open roof and two arms are open. Height of this apparatus from the floor is $40-70 \mathrm{~cm} .{ }^{26}$ Albino mice were placed gently by the tail in the centre of the plus shaped apparatus. Animals were allowed to move freely for 5 minutes. Observe the time spent in each arm and observe transition from enclosed arm to open arm. After performing test, apparatus was cleaned with alcohol $70 \%$.

\section{Results and discussion}

The result was analyzed by applying SPSS (Statistical Package for Social Sciences) 19. We took the mean of all values and then treated Group II and I were compared with control and with each other. The significance of difference between means was determined by applying two way ANOVA (analysis of variance) followed by post hoc Tukeys test. Value of $p<0.05$ is considered significant, $p<0.01$ is moderately significant and $p<0.001$ is highly significant.

Allopathic medicines have many adverse effects so we move to natural remedies to treat different diseases. Here we took coconut milk to check different parameters of CNS activity and our results show that coconut milk possesses anxiolytic activity. Table 1 shows the effect of coconut milk on head dip activity (Figure 1).

Table I Effect of different doses of coconut milk on head dip activity

\begin{tabular}{|c|c|c|c|}
\hline Drugs & Baseline & 7 Days & I5 Days \\
\hline $\begin{array}{l}\text { Control }(0.4 \mathrm{ml} \\
\text { Distill water })\end{array}$ & $25.5 \pm 0.84$ & $21.8 \pm 1.03$ & $21.3 \pm 1.15$ \\
\hline $\begin{array}{l}\text { Treated I } \\
\text { (Coconut Milk } \\
0.4 \mathrm{ml} \text { ) }\end{array}$ & $21.3 \pm 0.82$ & $20.8 \pm 0.78^{15}$ & $\mid \mathrm{I} .4 \pm 0.5 \mathrm{I} * * * \downarrow$ \\
\hline $\begin{array}{l}\text { Treated II } \\
\text { (Coconut Milk } \\
0.6 \mathrm{ml} \text { ) }\end{array}$ & $25.5 \pm 0.70$ & $13.9 \pm 0.87^{* * *} \downarrow \$ \$ \$ \downarrow$ & $12.3 \pm 1.12^{* * *} \downarrow^{15}$ \\
\hline
\end{tabular}

Initially when mice were placed in head dip apparatus, they tried to escape from the holes of apparatus due to neophobic response. ${ }^{26}$ So on exposure to apparatus anxiety developed due to state of fear, so decrease in number of escapes after administration of coconut milk, show anxiolytic property of it. In Table 1 we got highly significant result $(\mathrm{p}<0.001)$ as compared to control after 15 days dosing by both the doses. It shows that coconut milk reduces the anxiety (Table $2 \&$ Figure 2). 


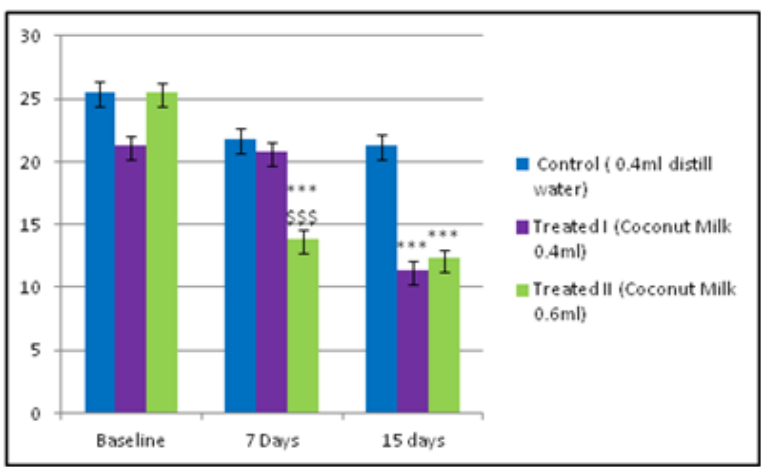

Figure I Effect of different doses of coconut milk on head dip activity. Two way Anova was performed for statistical analysis followed by post hoc Tukeys test. P values were represented as IS Insignificant $* * * \quad p<0.00$ I: Highly significant when compared with control. IS Insignificant $\$ \$ \$ p<0.00$ I: Highly significant when compared within groups.

Table 2 Effect of different doses of coconut milk on cage crossing activity

\begin{tabular}{llll}
\hline Drugs & Baseline & 7 Days & I5 Days \\
\hline & & & \\
Control (0.4ml Distill water) & $7.1 \pm 0.73$ & $6.7 \pm 0.94$ & $7.0 \pm 0.66$ \\
Treated I (Coconut Milk 0.4ml) & $7.3 \pm 0.83$ & $5.0 \pm 0.56 * * * \downarrow$ & $3.8 \pm 0.63^{* * *} \downarrow$ \\
Treated II (Coconut Milk 0.6ml) & $7.4 \pm 0.8$ I & $4.0 \pm 0.66 * * * \downarrow^{\text {IS }}$ & $2.6 \pm 0.5$ I*** $\downarrow$ Is \\
\hline
\end{tabular}

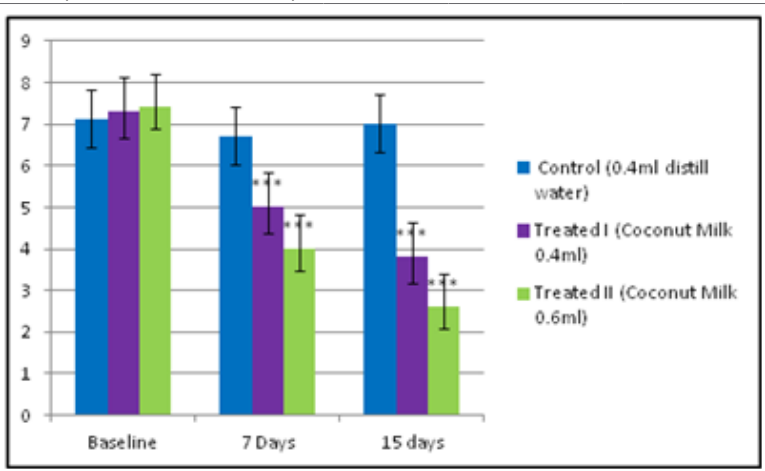

Figure 2 Effect of different doses of coconut milk on Cage crossing activity. Two way Anova was performed for statistical analysis followed by post hoc Tukeys test. $P$ values were represented as $* * * p<0.00$ I: Highly significant when compared with control. IS Insignificant when compared within groups.

Initially when mice were placed in cage crossing apparatus, due to state of fear mice crossed the cage several times. However, after administration of coconut milk number of crossing decreased, it shows that coconut milk possesses anxiolytic property. Moreover, we got highly significant result (Table 3a \& Figure 3a) (Table 3b \& Figure 3b).

Table 3a Effect of different doses of coconut milk on central square activity (open field)

\begin{tabular}{|c|c|c|c|}
\hline Drugs & Baseline & 7 Days & I5 Days \\
\hline Control (0.4ml Distill water) & $8.7 \pm 0.67$ & $8.5 \pm 0.65$ & $9.1 \pm 0.56$ \\
\hline Treated I (Coconut Milk 0.4ml) & $8.9 \pm 0.87$ & $\mid 4.6 \pm 1.07 * * * \downarrow$ & $18.8 \pm 1.47^{* * *} \downarrow$ \\
\hline Treated II (Coconut Milk 0.6ml) & $8.6 \pm 0.51$ & $14.4 \pm 1.17^{* * * *} \downarrow^{15}$ & $17.4 \pm 1.26 * * * \downarrow^{15}$ \\
\hline
\end{tabular}

Table 3b Effect of different doses of coconut milk on peripheral square activity (open field)

\begin{tabular}{|c|c|c|c|}
\hline Drugs & Baseline & 7 Days & I5 Days \\
\hline Control (0.4ml Distill water) & $263.9 \pm 1.64$ & $260 \pm 0.99$ & $26 I \pm 1.42$ \\
\hline Treated I (Coconut Milk 0.4ml) & $262 \pm 1.30$ & $109 \pm 1.22 * * * \downarrow$ & $56.8 \pm 1.11 * * * \downarrow$ \\
\hline Treated II (Coconut Milk 0.6ml & $264 \pm 1.21$ & $89.2 \pm 0.98 * * * \downarrow^{\$ \$ \$} \downarrow$ & $\downarrow 19.3 \pm 1.0 * * * \$ \$ \$$ \\
\hline
\end{tabular}

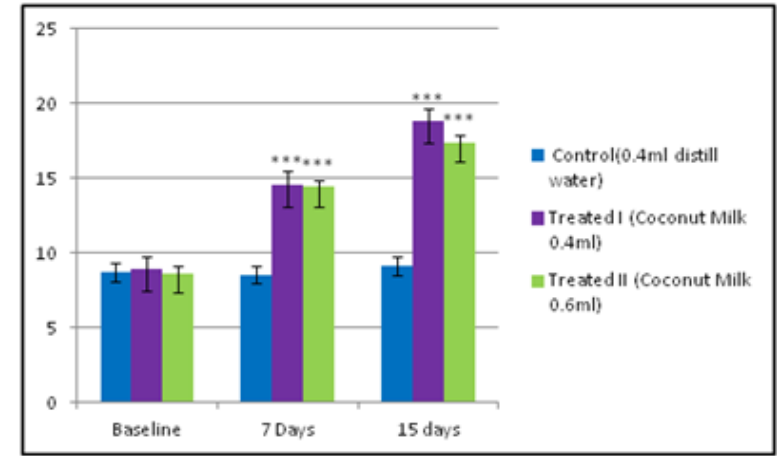

Figure 3a Effect of different doses of coconut milk on Central square activity (Open Field).

Two way Anova was performed for statistical analysis followed by post hoc Tukeys test. $P$ values were represented as $* * * p<0.001$ : Highly significant when compared with control. IS Insignificant when compared within groups.

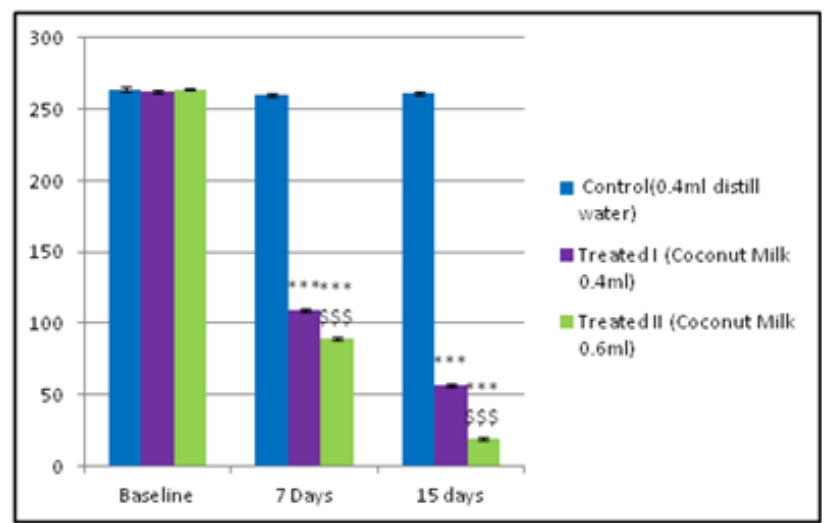

Figure 3b Effect of different doses of coconut milk on Peripheral square activity (Open Field).

Two way Anova was performed for statistical analysis followed by post hoc Tukeys test. $\mathrm{P}$ values were represented as $* * * \mathrm{p}<0.00 \mathrm{I}$ : Highly significant when compared with control. ${ }^{\$ \$} p<0.001$ : Highly significant when compared within groups.

Our results showed that the number of peripheral squares were highly significantly decreased while number of central squares were highly significant increased. This result shows that coconut milk administration reduced anxiety. Table 4 shows the effect of coconut milk on light \& dark model (time spent in light) (Figure 4).

Table 4 Effect of different doses of coconut milk on time spent in light area (light and dark box)

\begin{tabular}{|c|c|c|c|}
\hline Drugs & Baseline & 7 Days & I 5 Days \\
\hline $\begin{array}{l}\text { Control } 0.4 \mathrm{ml} \text { Distill } \\
\text { water }\end{array}$ & $117.5 \pm 1.35$ & $116.4 \pm 1.70$ & $117.3 \pm 1.61$ \\
\hline $\begin{array}{l}\text { Treated I (Coconut } \\
\text { Milk } 0.4 \mathrm{ml} \text { ) }\end{array}$ & $117.6 \pm 1.44$ & $123.4 \pm 1.55^{* * * *} \uparrow$ & $132.2 \pm 0.99 * * * \uparrow$ \\
\hline $\begin{array}{l}\text { Treated II (Coconut } \\
\text { Milk } 0.6 \mathrm{ml} \text { ) }\end{array}$ & || $7.7 \pm|.5|$ & $121.5 \pm\left. 1.3\right|^{* * *} \uparrow^{15}$ & $|28.7 \pm| .22^{* * *} \uparrow^{\$ \$} \downarrow$ \\
\hline
\end{tabular}

Time spend in light box was increased which shows the anxiolytic effect of coconut milk. Our result was highly significant. Table 5 shows the effect of coconut milk on elevated plus maze model (time spent in open arm) (Figure 5).

Our result was highly significant as times spend in open arm was increased, which showed the anxiolytic activity of coconut milk. 
Table 5 Effect of different doses of coconut milk on time spent in open arm (elevated plus maze)

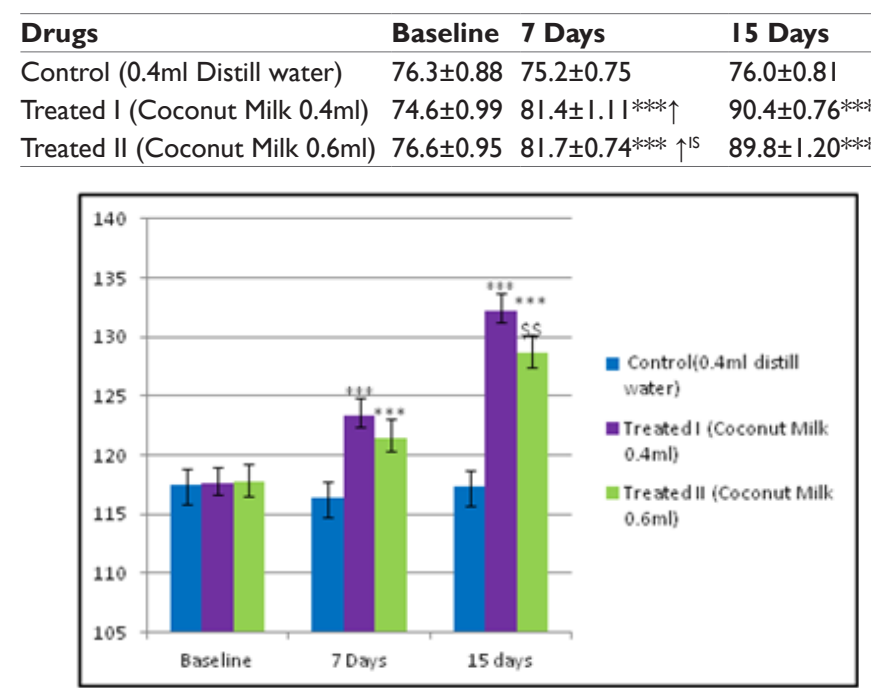

Figure 4 Effect of different doses of coconut milk on Time spent in Light area (Light and Dark box).

Two way Anova was performed for statistical analysis followed by post hoc Tukeys test. $P$ values were represented as $* * * \mathrm{p}<0.00 \mathrm{I}$ : Highly significant when compared with control.

IS Insignificant $\$ \$ p<0.01$ : Moderately significant when compared within groups.

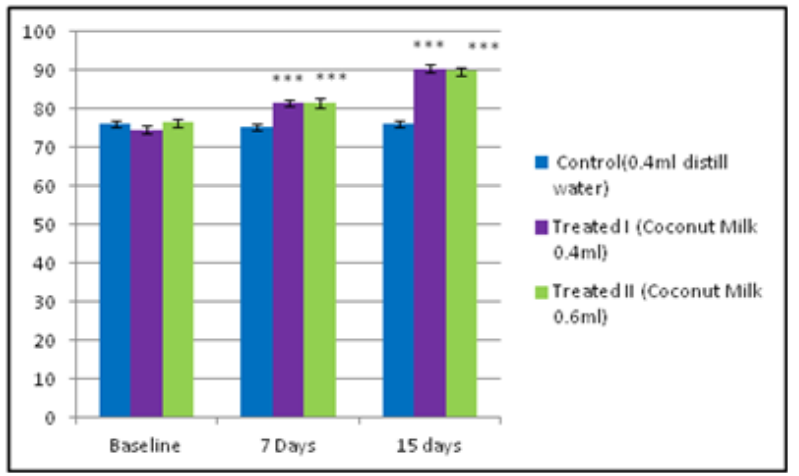

Figure 5 Effect of different doses of coconut milk on Time spent in Open arm (Elevated Plus Maze).

Two way Anova was performed for statistical analysis followed by post hoc Tukeys test. P values were represented as $* * * p<0.00$ I: Highly significant when compared with control.

IS Insignificant when compared within groups.

The mechanism of action of anxiolytic drug is it mediates the effect of the GABA neurotransmitter by binding with receptor of GABA, which causes opening of chloride ion and causes hyperpolarization. ${ }^{27}$ Due to antioxidant property of coconut milk, it gives neuroprotective effects. The antioxidant effect of coconut milk is due to presence of vitamin $\mathrm{C} \& \mathrm{E}$, selenium and zinc. Hence, due to the presence of these agents coconut milk produces relief from anxiety. Coconut milk is used commonly in juices and drinks and this anxiolytic property of coconut milk could be very beneficial for people suffering from different kinds of anxiety.

\section{Conclusion}

From the above study, we came to conclude that coconut milk produces anxiolytic effect at both the doses however increasing the dose did not change the anxiolytic effect as shown by our results. Further studies need to be carried out to determine the exact mechanism by which coconut milk produces the anxiolytic effect.

\section{Acknowledgements}

None.

\section{Conflicts of interest}

There is neither any financial interest nor any conflict of interest.

\section{References}

1. Association AP. Diagnostic and statistical manual of mental disorders (DSM-5®), American Psychiatric Pub, USA. 2013.

2. Quitkin FM, Rifkin A, Kaplan J, et al. Phobic anxiety syndrome complicated by drug dependence and addiction: a treatable form of drug abuse. Arch Gen Psychiatry. 1972;27(2):159-162.

3. Healy D. Psychiatric drugs explained. Elsevier Health Sciences, USA, 2008. p. 360.

4. Etkin A, Prater KE, Schatzberg AF, et al. Disrupted amygdalar subregion functional connectivity and evidence of a compensatory network in generalized anxiety disorder. Arch Gen Psychiatry. 2009;66(12):1361-1372.

5. Lader M. Generalized anxiety disorder, in Encyclopedia of Psychopharmacology. Springer, Germany, 2005. p. 699-702.

6. Stein DJ. Obsessive-compulsive disorder. Lancet. 2002;360(9330):397-405.

7. Stein MB, Stein DJ. Social anxiety disorder. Lancet. 2008;371(9618):1115-1125.

8. Gene Cos N. Post-traumatic stress disorder: the management of ptsd in adults and children in primary and secondary care. Psychiatrist. 2006;30:357-357.

9. Schoenhuber R, Gentilini M. Anxiety and depression after mild head injury: a case control study. J Neurol Neurosurg Psychiatry. 2988;51(5):722-724.

10. El Miedany YM, El Rasheed AH. Is anxiety a more common disorder than depression in rheumatoid arthritis? Joint Bone Spine. 2002;69(3):300-306.

11. Hiott DW, Labbate L. Anxiety disorders associated with traumatic brain injuries. NeuroRehabilitation. 2002;17(4):345-355.

12. McLeod BD, Wood JJ, Weisz JR. Examining the association between parenting and childhood anxiety: A meta-analysis. Clin Psychol Rev. 2007;27(2):155-172.

13. Lader M. Treatment of anxiety. BMJ. 1994;309(6950):321-324.

14. Reinecke MA, Ryan NE, DuBOIS DL. Cognitive-behavioral therapy of depression and depressive symptoms during adolescence: a review and meta-analysis. J Am Acad Child Adolesc Psychiatry. 1998;37(1):26-34.

15. Dalrymple KL. Combined treatments (medications plus psychotherapy). The Encyclopedia of Clinical Psychology. 2005. p. 1-6.

16. Zohar J, Westenberg H. Anxiety disorders: a review of tricyclic antidepressants and selective serotonin reuptake inhibitors. Acta Psychiatr Scand Suppl. 2000;403:39-49

17. Bonnet F, Irving K, Terra JL, et al. Anxiety and depression are associated with unhealthy lifestyle in patients at risk of cardiovascular disease. Atherosclerosis. 2005;178(2):339-344.

18. Yong JW, Ge $\mathrm{L}, \mathrm{Ng} \mathrm{YF}$, et al. The chemical composition and biological properties of coconut (Cocos nucifera L.) water. Molecules. 2009;14(12):5144-5164. 
19. Radenahmad N, Saleh F, Sawangjaroen K, et al. Young coconut juice, a potential therapeutic agent that could significantly reduce some pathologies associated with Alzheimer's disease: novel findings. $\mathrm{Br} J$ Nutr. 2011;105(5):738-746.

20. Ganguly S. Health benefits of coconut in the Asian cuisines: A Review. J Biol Chem Res. 2013;30(2):517-521.

21. Lieberman S, Enig MG, Preuss HG. A review of monolaurin and lauric acid: natural virucidal and bactericidal agents. Alternative $\&$ Complementary Therapies. 2006;12(6):310-314.

22. File SE, Wardill AG. Validity of head-dipping as a measure of exploration in a modified hole-board. Psychopharmacologia. 1975;44(1):53-59.

23. Clark G, Koester AG, Pearson DW. Exploratory behavior in chronic disulfoton poisoning in mice. Psychopharmacologia. 1971;20(2):169-171.
24. Hall C, Ballachey EL. A study of the rat's behavior in a field. A contribution to method in comparative psychology. University of California Publications in Psychology. 1932;6:1-2.

25. Sana Sarfaraz, Hummera Khatoon, Haleema Moin, et al. Evaluation of anxiolytic effect of pineapple juice. RRJPPS. 2005;4(3):38-45.

26. Carobrez A, Bertoglio L. Ethological and temporal analyses of anxietylike behavior: the elevated plus-maze model 20 years on. Neurosci Biobehav Rev. 2005;29(8):1193-1205.

27. Pollack MH, Roy Byrne PP, Van Ameringen M, et al. The selective GABA reuptake inhibitor tiagabine for the treatment of generalized anxiety disorder: results of a placebo-controlled study. J Clin Psychiatry. 2005;66(11):1401-1408. 